\title{
Degradation of ambient carbonyl sulfide by Mycobacterium spp. in soil
}

\author{
Correspondence \\ Yoko Katayama \\ katayama@cc.tuat.ac.jp
}

Received 3 July 2007

Revised 26 September 2007

Accepted 5 October 2007

\section{Hiromi Kato, Masahiko Saito, † Yoshiko Nagahatał and Yoko Katayama}

Department of Environmental and Natural Resource Science, Graduate School of Agriculture, Tokyo University of Agriculture and Technology, Fuchu, Tokyo 183-8509, Japan

\begin{abstract}
The ability to degrade carbonyl sulfide (COS) was confirmed in seven bacterial strains that were isolated from soil, without the addition of COS. Comparative 16S rRNA gene sequence analysis indicated that these isolates belonged to the genera Mycobacterium, Williamsia and Cupriavidus. For example, Mycobacterium sp. strain THI401, grown on PYG agar medium, was able to degrade an initial level of 30 parts per million by volume COS within $1 \mathrm{~h}$, while $60 \%$ of the initial COS was decreased by abiotic conversion in $30 \mathrm{~h}$. Considering natural COS flux between soil and the atmosphere, COS degradation by these bacteria was confirmed at an ambient level of 500 parts per trillion by volume (p.p.t.v.), using sterilized soil to cultivate the bacterium. Autoclave sterilization of soil resulted in a small amount of COS emission, while Mycobacterium spp. degraded COS at a faster rate than it was emitted from the soil, and reduced the COS mixing ratio to a level that was lower than the ambient level: THI401 degraded COS from an initial level of 530 p.p.t.v. to a level of 330 p.p.t.v. in 30 h. These results provide experimental evidence of microbial activity in soil as a sink for atmospheric COS.
\end{abstract}

\section{INTRODUCTION}

Carbonyl sulfide (COS) is the most abundant sulfur compound in the atmosphere, with its tropospheric mixing ratios reported to be around 500 parts per trillion by volume (p.p.t.v.) (Torres et al., 1980; Bandy et al., 1992; Chin \& Davis, 1995). COS is regarded as a dominant source of stratospheric sulfate aerosol, which influences the earth's radiation budget, and therefore the climate (Crutzen, 1976). Therefore, attention is being focused on both sources and sinks of COS (Andreae \& Crutzen, 1997; Watts, 2000).

Soil is a major sink for atmospheric COS (Castro \& Galloway, 1991; Andreae \& Crutzen, 1997; Kesselmeier et al., 1999; Kuhn et al., 1999; Simmons et al., 1999; Watts, 2000). Changes in temperature and water content, as well as repeated exposure of soil to COS, affect the rate of COS consumption by soil (Bremner \& Banwart, 1976; Lehmann \& Conrad 1996; Kesselmeier et al., 1999; Saito et al., 2002). Therefore, soil micro-organisms carrying COS-degrading activity have been regarded as having a dominant role as a sink for atmospheric COS.

Biological degradation of COS has been examined on an enzyme level in several organisms that consume $\mathrm{CO}_{2}$.

tPresent address: Tochigi Prefectural Agricultural Experiment Station, Japan.

‡Present address: Department of Biochemistry \& Integrative Medical Biology, School of Medicine, Keio University, Japan.

Abbreviations: CA, carbonic anhydrase; COS, carbonyl sulfide; p.p.m.v., parts per million by volume; p.p.t.v., parts per trillion by volume.
Carbonic anhydrase (CA), a ubiquitous enzyme that catalyses reversible hydration between $\mathrm{CO}_{2}$ and $\mathrm{HCO}_{3}^{-}$, reacts with $\mathrm{COS}\left(\mathrm{COS}+\mathrm{H}_{2} \mathrm{O} \rightarrow \mathrm{CO}_{2}+\mathrm{H}_{2} \mathrm{~S}\right)$ because of the structural analogy of $\mathrm{CO}_{2}$ and $\mathrm{COS}$. This process has been confirmed in rat hepatocytes and erythrocytes (Chengelis \& Neal, 1979), higher plants (Protoschill-Krebs \& Kesselmeier, 1992), algae (Protoschill-Krebs et al., 1995), lichens (Gries et al., 1994), and cyanobacteria (Miller et al., 1989; Badger \& Price, 1990). Micro-organisms possessing the ability to metabolize $\mathrm{CO}_{2}$ are considered to be involved in COS consumption (Conrad, 1996). Nevertheless, it is unclear which pathways soil micro-organisms employ to degrade atmospheric COS because there have been few reports on isolation of COS-degrading microbes from soil environments. Furthermore, most studies on COS degradation by micro-organisms have been conducted under favourable growth conditions for the microorganism tested. However, soil environments differ from such favourable conditions in both nutrient and physicochemical aspects. Most of the COS mixing ratios used for experiments of microbial degradation have been higher than the ambient levels of COS. Conrad \& Meuser (2000) showed that COS is consumed by a different biological activity at an ambient mixing ratio than that used at higher mixing ratios, indicating that bacteria utilizing COS at higher mixing ratios are not always able to use the gas at ambient levels.

In this study, we report COS-degrading activity in heterotrophic bacteria that were isolated from soil environments. The degradation of COS was confirmed at 
an ambient mixing ratio, using sterilized soil as the incubation medium for the isolates. The results provide experimental evidence for the role of soil bacteria as a sink for atmospheric COS.

\section{METHODS}

Isolation of heterotrophic bacteria. Heterotrophic bacteria were isolated from four different soil samples: farm soil at the Tokyo University of Agriculture and Technology (Tokyo), soil from near sewage-disposal equipment at a cattle farm (Tochigi Prefecture), and two forest soils (Aomori Prefecture and Yamanashi Prefecture). Soil was suspended in sterilized water, and then streaked onto 10-fold diluted Trypto-soy agar medium, $\mathrm{pH} 7.3$ (Eiken), containing $\left(\mathrm{g}^{-1}\right)$ : 1.5 tryptone, 0.5 soy peptone and $0.5 \mathrm{NaCl}$. To 11 of this medium, $100 \mathrm{ml}$ soil extract and $13.5 \mathrm{~g}$ Bacto agar (Difco) (final agar content, $15.0 \mathrm{~g}$ ) were added. Unless otherwise indicated, incubations were carried out in ambient air at $30{ }^{\circ} \mathrm{C}$ in the dark. Colonies were randomly picked, purified, and subsequently examined for COSdegradation activity on a PYG slant, as described below. The soil extract was prepared by autoclaving $400 \mathrm{~g}$ soil suspended in 11 distilled water at $121{ }^{\circ} \mathrm{C}$ for $30 \mathrm{~min}$, and then filtering through filter paper (No. 2 filter paper; Advantec).

Isolated bacteria were maintained on a PYG slant, $\mathrm{pH}$ 7.2, containing $\left(\mathrm{g} \mathrm{l}^{-1}\right)$ : 2.0 polypeptone (Nihon Seiyaku), 1.0 Bacto yeast extract (Difco), 0.5 glucose, and 15.0 Bacto agar.

Degradation of $\mathbf{3 0}$ p.p.m.v. COS on a PYG slant. The isolated bacterium was streaked on a PYG slant. The PYG slant was prepared in a glass tube of $20 \mathrm{~cm}$ length and $2 \mathrm{~cm}$ i.d., and it contained $10 \mathrm{ml}$ PYG medium to make a headspace volume of $40 \mathrm{ml}$. When colonies were formed, the cap of the test tube was changed from a silicone sponge cap to a butyl cap, and $11.5 \mu \mathrm{l}$ COS gas [105000 parts per million by volume (p.p.m.v.), with $\mathrm{N}_{2}$ as the balance gas; Nissan Tanaka] was added to the headspace to make a final COS mixing ratio of 30 p.p.m.v. At the times indicated (Figs 1 and 2), $50 \mu$ l headspace gas was obtained using a gas-tight microsyringe, and then injected into a gas chromatograph to measure the mixing ratio of COS, as described below. The moist condition of a sealed test tube containing agar medium gradually decreases the COS mixing ratio due to hydrolysis of COS with water (Ferm, 1957); therefore, bacterial COS degradation was evaluated by comparing the chemical degradation of COS based on a control slant that was not inoculated. Experiments were carried out in duplicate, under aerobic conditions, because anaerobic conditions have been known to inhibit COS consumption by soil (Lehmann \& Conrad, 1996).

Degradation of 30 p.p.m.v. COS in soil. The isolate was preincubated in a test tube containing $10 \mathrm{ml}$ PYG-Low medium, with reciprocal shaking at 120 r.p.m. for 3 days. The PYG-Low medium, $\mathrm{pH} 7.2$, contained $\left(\mathrm{mg} \mathrm{l}^{-1}\right)$ : 300 Bacto peptone (Difco), 150 Bacto yeast extract, 150 glucose, $298 \mathrm{Na}_{2} \mathrm{HPO}_{4}$, and $122 \mathrm{KH}_{2} \mathrm{PO}_{4}$. To make an initial cell density of $10^{6}$ c.f.u. (g wet soil) ${ }^{-1}$, the cell suspension in the PYG-Low culture was diluted 100-fold with sterilized distilled water. This dilution reduced the carryover of the constituents of the PYG-Low medium so that they were present in negligible amounts for the experiment of bacterial COS degradation in soil. The resultant cell suspension $(1.5 \mathrm{ml})$ was added by dropping onto sterilized soil $(4 \mathrm{~g})$, which was placed in a glass test tube, to give a water content of the soil of $58 \%$ (water weight/dry soil weight). The tube was then sealed with a butyl cap. As a control, $1.5 \mathrm{ml}$ sterilized distilled water was added to the soil. After an incubation of $8-10$ days at $25{ }^{\circ} \mathrm{C}$ to stabilize the cell density, headspace gas in the test tube was replaced with fresh air by purging filter-sterilized air. Then, COS gas was added to make a final mixing ratio of 30 p.p.m.v., as described above, and the decrease in the level of COS was monitored.

Soil (Andosol) used for the incubation of cells was obtained from the surface layer of soil $(0-5 \mathrm{~cm})$ at the university farm, air-dried for 17 days at room temperature, sieved with a $2 \mathrm{~mm}$ mesh, and then stored at $4{ }^{\circ} \mathrm{C}$. Organic carbon content, $\mathrm{pH}$ and maximum waterholding capacity of this soil were $8.2 \%$ (w/w, dry soil), 6.2 and $90 \%$ (water weight/dry soil weight), respectively. The stored soil was sterilized by autoclaving at $121{ }^{\circ} \mathrm{C}$ for $30 \mathrm{~min}$ before use. The sterility of the soil was confirmed by streaking the soil suspension onto PYG agar medium.

Comparison of bacterial COS degradation between the slant and the soil. $\mathrm{COS}$ degradation curves of the isolates at $25{ }^{\circ} \mathrm{C}$ were

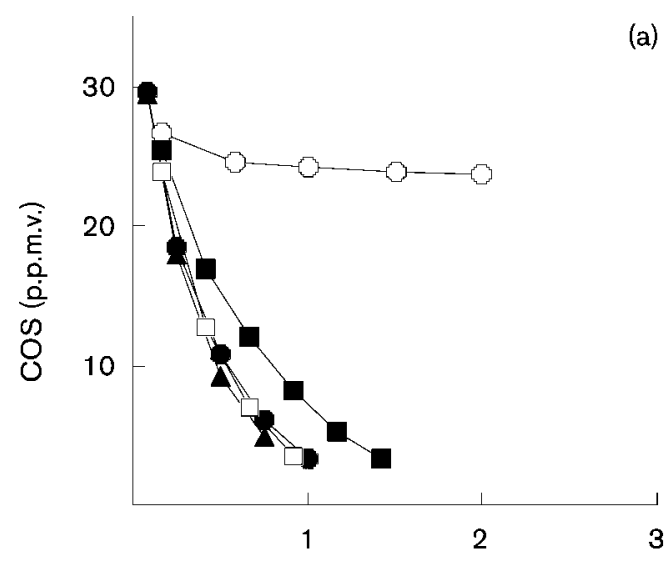

(a)

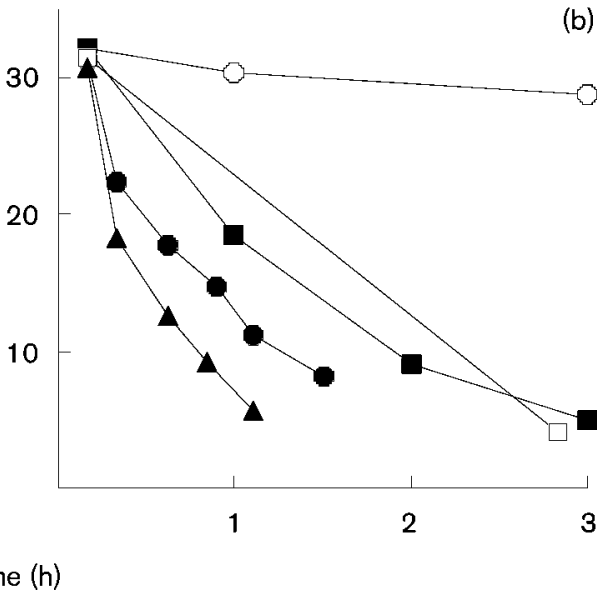

Fig. 1. Degradation of 30 p.p.m.v. COS by Mycobacterium spp. grown on a PYG slant (a) and in soil (b). The strains tested were Mycobacterium sp.: $\bullet$, THI401; $\mathbf{Q}$, THI402; $\square$, THI404; $\mathbf{\Delta}$, THI405. $\bigcirc$, Negative control [uninoculated sterilized PYG medium (a), or soil (b)]. The points on the curves represent mean values of duplicates - deviation from the mean was less than $10 \%$. 

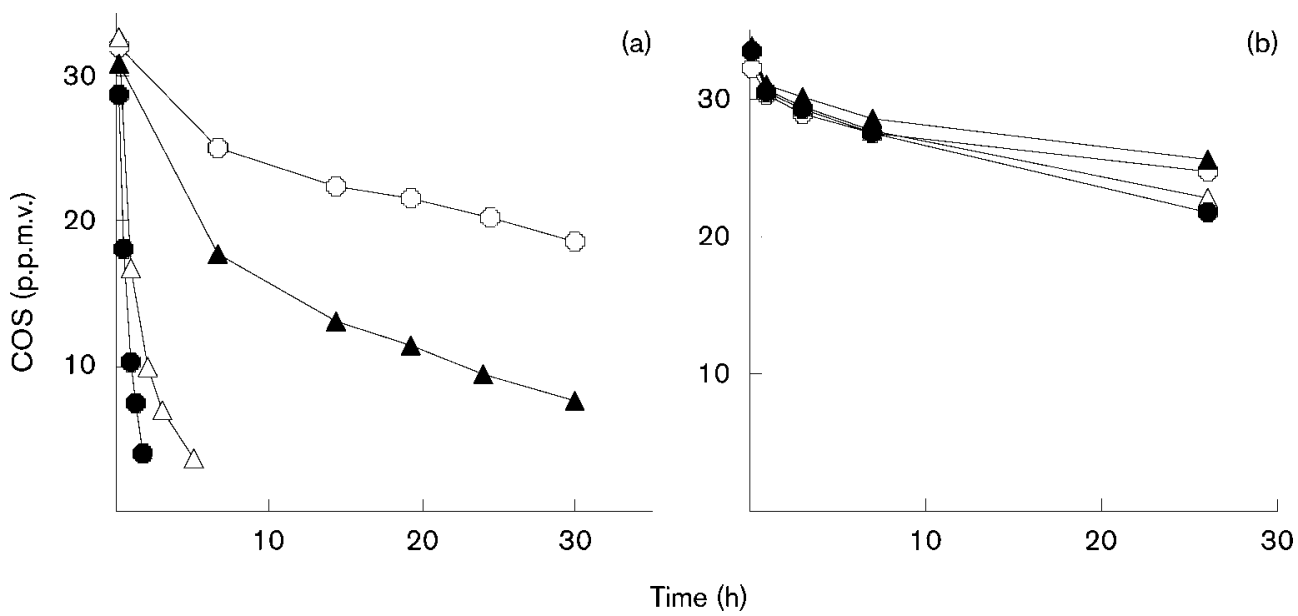

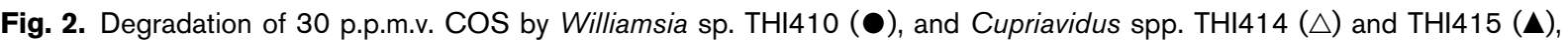
grown on a PYG slant (a) and in soil (b). $\bigcirc$, Negative control [uninoculated sterilized PYG medium (a), or soil (b)]. The points on the curves represent mean values of duplicates - deviation from the mean was less than $10 \%$.

fitted to the exponential function $C_{(t)}=C_{0} \mathrm{e}^{-k t}\left(R^{2}>0.8\right)$, where $C_{(t)}$ is the mixing ratio of COS given at the time $t(\mathrm{~h}), C_{0}$ is the initial COS mixing ratio, and $k$ is the rate constant (per hour per test tube). The rate constants of COS degradation obtained by using the cells grown on the slant and in the soil were compared to determine the effect of incubation in soil on the COS-degrading activity of the bacteria.

The number of bacterial cells was estimated based on the c.f.u. method. The cells on the slant medium were suspended in $10 \mathrm{ml}$ sterilized distilled water, and serial dilutions were plated onto PYG agar medium. The cells inoculated in the soil $(4 \mathrm{~g}$ soil plus $1.5 \mathrm{ml}$ cell suspension) were suspended in $14.5 \mathrm{ml}$ sterilized distilled water, and mixed thoroughly by vortexing for $2 \mathrm{~min}$. Then, the dilutions of the resultant suspension were plated onto PYG agar medium. The number of cells in the soil was counted at the time of inoculation, and then again after a 10 day incubation.

Degradation of ambient levels of cos in the soil. For the experiment carried out at the ambient mixing ratio of COS, a 51 gassampling bag (aluminized polyethylene bag; GL Science) was used to prepare a sufficient volume of headspace for air sampling. The bacterium was pre-incubated in PYG-Low medium, diluted with sterilized water, and dropped onto the sterilized soil $(5.3 \mathrm{ml}$ suspension per $14 \mathrm{~g}$ soil $)$ in a glass Petri dish $(8.8 \mathrm{~cm}$ i.d.). The initial cell density and the water content were $10^{6}$ c.f.u. ( $g$ wet soil) ${ }^{-1}$ and $58 \%$ (water weight/dry soil weight), respectively. After an incubation of 10 days, the slightly hardened soil was tilled with a sterilized spatula, and then the Petri dish with the soil, but without the lid, was placed in the gas-sampling bag. One corner of the bag had been cut off, and the inside was sterilized with $70 \%$ ethanol. At times $0,10,20$ and $30 \mathrm{~h}$, a $300 \mathrm{ml}$ sample of air was taken from the bag with a syringe, and loaded onto a pre-cryo column under liquid oxygen. After the cryogenic concentration of COS, the column was heated to $100{ }^{\circ} \mathrm{C}$ in $2 \mathrm{~min}$, using a Flash Sampler (FLS-1; Shimadzu) to introduce the sample into the gas chromatograph. Measurement was performed twice to ensure accurate determination of the low level of COS. We obtained the reproducibility of the bacterial degradation of the ambient level of COS by performing repeated experiments.

CoS analysis. COS was measured by a gas chromatograph (GC-14B; Shimadzu) equipped with a flame photometric detector, and a glass column packed with Porapak QS (50-80 mesh; Waters Associates), as described previously (Katayama et al., 1992). Nitrogen was used as the carrier gas, and the flow rate was $43 \mathrm{ml} \mathrm{min}{ }^{-1}$. The temperatures of the injector, the column and the detector were 150,110 and $150{ }^{\circ} \mathrm{C}$, respectively. The pre-cryo column for the analysis of ambient COS was packed with 1,2,3-Tris(2-cyanoethoxy)propane (GL Science). Deviations from the mean of duplicate samples were found to deviate from the mean by less than 10 and $20 \%$ for the analyses of p.p.m.v. and p.p.t.v. levels, respectively. The detection limits for COS with direct injection to the gas chromatograph, and for cryogenic concentration, were 3.9 p.p.m.v. and 260 p.p.t.v., respectively.

Phylogenetic analysis. The isolate was grown in PYG liquid medium, and harvested by centrifugation. DNA was extracted from the cell pellet by using an Isoplant DNA extraction kit (Nippon Gene). Partial 16S rRNA between the 357-907 nt region (Escherichia coli numbering) (Muyzer et al., 1995) was amplified by PCR. The primers used here were 16S357F (5'-CCTACGGGAGGCAGGCAG$\left.3^{\prime}\right)$ and 16S907R (5'-CCCCGTCAATTCCTTTGAGTTT-3'). PCR products were purified using an UltraClean 15 DNA purification kit (Mo Bio Laboratory). Sequencing was performed with a BigDye Terminator Cycle Sequencing Ready Reaction DNA sequencing kit (Applied Biosystems) and an ABI Prism 377 DNA sequencer (Applied Biosystems). The 16S rRNA gene sequences were compared with sequences in the GenBank database using BLAST (Altschul et al., 1990). The nucleotide sequences of $16 \mathrm{~S}$ rRNA gene of COS-degrading bacteria isolated in this study have been deposited in the DNA Data Bank of Japan under the following accession numbers: THI401, AB206556; THI402, AB206557; THI404, AB206559; THI405, AB206560; THI410, AB206564; THI414, AB206569; THI415 and AB206568.

\section{RESULTS}

\section{Isolation of COS-degrading bacteria}

Bacterial colonies were grown on 10-fold diluted Tryptosoy agar medium, and randomly isolated. A total of 112 heterotrophic bacteria were obtained from four soil samples (approx. 30 isolates per soil sample). Screening 
for the isolates that carried the ability to degrade 30 p.p.m.v. COS was performed by using cells grown on a PYG slant. From the forest soil obtained in Aomori Prefecture and Yamanashi Prefecture, 19 out of 27 isolates, and 8 out of 32 isolates, respectively, produced significant decreases in the level of COS. The farm soil from the university, and the cattle-farm soil, produced 2 out of 23 isolates, and two out of 30 isolates, respectively, that showed COS-degradation activity. Although the frequencies of COS-degrading bacteria found in the four types of soil varied among the soil samples, heterotrophic COS degraders were found in all the soil samples tested.

Seven isolates (THI401, THI402, THI404, THI405, THI410, THI414 and THI415) were used for the further experiments because they showed both stable COS degradation activity and growth. THI401, THI402 and THI404 were isolated from forest soil in Aomori Prefecture, THI405, THI414 and THI415 were isolated from forest soil in Yamanashi Prefecture, and THI410 was isolated from cattle-farm soil in Tochigi Prefecture. Comparative 16S rRNA gene sequence analysis indicated that THI401, THI402, THI404 and THI405 were rapidgrowing strains of Mycobacterium spp., and that THI410 belonged to the genus Williamsia. THI414 and THI415 were related to the genus Cupriavidus.

\section{COS degradation in the PYG slant and the soil}

We compared COS degradation by the bacterial isolates grown on the slant and in the soil to determine whether the bacteria were able to exhibit COS degradation in a soil environment. Figs 1 and 2 show COS degradation by bacteria grown on the PYG slant and in the soil. Initially, 30 p.p.m.v. COS in the test tube containing an uninoculated slant was reduced slowly to about $60 \%$ of the original level in $30 \mathrm{~h}$ (Fig. 2a); this was probably caused by abiotic and irreversible hydrolysis of COS (Ferm, 1957; Elliott et al., 1989) on the surface of the agar medium. Mycobacterium spp. strains THI401, THI402, THI404 and THI405 degraded 30 p.p.m.v. COS to the detection limit within $2 \mathrm{~h}$ (Fig. 1a). These four strains exhibited a level of COS degradation activity in soil that was similar to that on the PYG slant; they degraded COS to the detection limit within $3 \mathrm{~h}$ (Fig. 1b). The rate constants of COS degradation observed in the PYG slant tube and the soil are summarized in Table 1. The mycobacterial strains showed lower rate constants in the soil than in the PYG tube. Growth of these isolates was estimated based on cell number, and the results indicated that THI402, THI404 and THI405 exhibited a level of growth in soil that was similar to that in the slant culture.

Williamsia sp. strain THI410, and Cupriavidus spp. strains THI414 and THI415, were able to degrade COS in the PYG slant tube, but the rate constants were lower than those obtained for the strains of Mycobacterium spp. (Table 1, Fig. 2a). However, in soil, these three strains were unable to degrade COS (Fig. 2b). THI410 and THI414 showed large reductions in the rate constants for COS degradation in soil, to $1.3 \%$ and $3.0 \%$ of the original, respectively. Based on specific activity of COS degradation (Table 1), culturing the bacteria in soil appeared to have a negative effect on the growth of THI410, and on the COS-degradation activity of THI414 and THI415, while it did not have a negative effect on COS degradation by the mycobacterial isolates.

Production of $\mathrm{H}_{2} \mathrm{~S}$ during $\mathrm{COS}$ degradation was observed for several isolates, while it was not observed in the uninoculated control. Fig. 3 shows $\mathrm{H}_{2} \mathrm{~S}$ production by Mycobacterium sp. THI401, and Williamsia sp. THI410, both of which were grown on PYG agar slants. According to the decrease in the level of COS, a volume of $\mathrm{H}_{2} \mathrm{~S}$ that

Table 1. Comparison of rate constants for COS degradation by the isolates grown on the PYG slant and the soil

\begin{tabular}{|c|c|c|c|c|c|c|}
\hline \multirow[t]{2}{*}{ Organism } & \multicolumn{2}{|c|}{ Rate constant ${ }^{\star}$} & \multicolumn{2}{|c|}{ Cell number $\dagger$} & \multicolumn{2}{|c|}{$\begin{array}{c}10^{10} \times \text { Specific activity } \\
\left(h^{-1} \text { c.f.u. }^{-1}\right)\end{array}$} \\
\hline & PYG slant & Soil & PYG slant & Soil & PYG slant & Soil \\
\hline Mycobacterium sp. THI401 & $2.3 \ddagger$ & 0.97 & $3.1 \times 10^{10}$ & $3.4 \times 10^{8}$ & 0.76 & 28 \\
\hline Mycobacterium sp. THI402 & $1.6 \ddagger$ & 0.67 & $8.7 \times 10^{8}$ & $1.4 \times 10^{9}$ & 20 & 4.7 \\
\hline Mycobacterium sp. THI404 & $2.5 \ddagger$ & 0.77 & $1.5 \times 10^{10}$ & $1.9 \times 10^{9}$ & 1.7 & 4.0 \\
\hline Mycobacterium sp. THI405 & $2.7 \ddagger$ & 1.7 & $1.1 \times 10^{10}$ & $1.2 \times 10^{9}$ & 2.5 & 14 \\
\hline Williamsia sp. THI410 & $1.2 \ddagger$ & 0.015 & $6.4 \times 10^{9}$ & $4.3 \times 10^{7}$ & 1.9 & 1.4 \\
\hline Cupriavidus sp. THI414 & 0.44 & 0.013 & $5.5 \times 10^{9}$ & $1.8 \times 10^{9}$ & 0.77 & 0.024 \\
\hline Cupriavidus sp. THI415 & 0.044 & 0.0090 & $3.7 \times 10^{9}$ & $1.6 \times 10^{9}$ & 0.075 & 0.001 \\
\hline Medium/soil\$ & 0.017 & 0.0088 & - & - & - & - \\
\hline
\end{tabular}

${ }^{*}$ The time course of COS degradation (per hour per tube) by the isolate was fitted to a regression curve: $C_{(t)}=C_{0} \mathrm{e}^{-k t}$, where $C_{(t)}$ is the mixing ratio of COS at the time $t(\mathrm{~h}), C_{0}$ is the initial mixing ratio of COS, $k$ is the rate constant. Deviations from the mean were less than $15 \%$ for duplicate samples.

$\dagger$ Cell number measured in c.f.u. per tube ${ }^{-1}$. Deviations from the mean were less than $30 \%$ for duplicate samples.

$\ddagger \mathrm{H}_{2} \mathrm{~S}$ production was detected during COS degradation.

$\S P Y G$ agar medium or soil sterilized by autoclaving. 


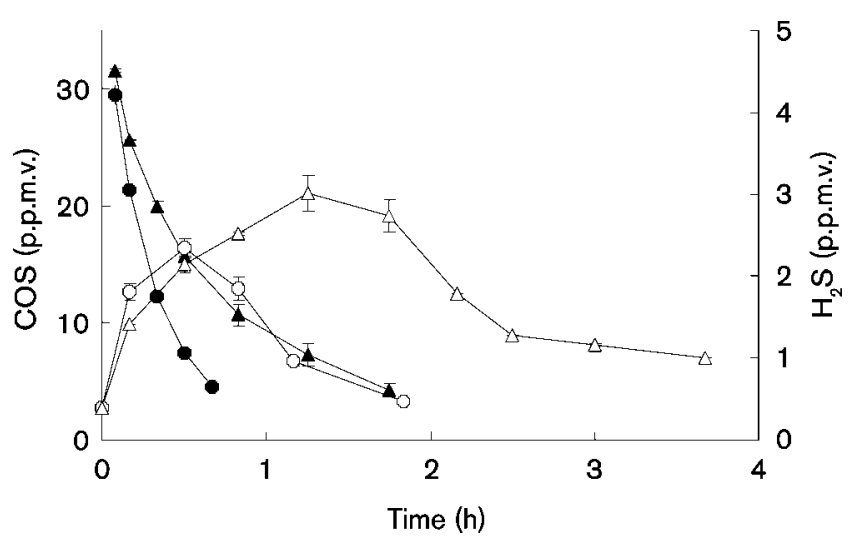

Fig. 3. Production of $\mathrm{H}_{2} \mathrm{~S}$ during the degradation of 30 p.p.m.v. COS in the tube containing the PYG slant. Closed symbols, COS degradation; open symbols, $\mathrm{H}_{2} \mathrm{~S}$ production. $\bullet, \bigcirc$, Mycobacterium sp. THI401; $\Delta, \triangle$, Williamsia sp. THI410. $\mathrm{H}_{2} \mathrm{~S}$ production was not detected (<0.39 p.p.m.v.) in the negative control (uninoculated sterilized medium). The points on the curves represent mean values of duplicates - deviation from the mean was less than $10 \%$.

was equivalent to about $8-10 \%$ of the initially added COS was detected in the headspace, and this then decreased upon further incubation. Similar levels of $\mathrm{H}_{2} \mathrm{~S}$ production were observed when Mycobacterium spp. THI402, THI404 and THI405 were grown on the PYG slant. Although Cupriavidus spp. THI414 and THI415 did not produce a detectable level ( $>0.39$ p.p.m.v.) of $\mathrm{H}_{2} \mathrm{~S}$ during degradation of 30 p.p.m.v COS, around 2 p.p.m.v. $\mathrm{H}_{2} \mathrm{~S}$ was detected when 300 p.p.m.v. COS was added. These results indicate that $\mathrm{H}_{2} \mathrm{~S}$ is an intermediate of $\mathrm{COS}$ degradation in the strains tested. When the experiment was carried out in soil, $\mathrm{H}_{2} \mathrm{~S}$ was not detected in the headspace gas.

\section{Degradation of ambient levels of COS}

The bacterial isolates were acclimatized to the sterilized soil, and then the soil was placed in the gas-sampling bag, into which ambient air was introduced. Fig. 4 shows the time courses of the COS mixing ratios in the bag. The initial COS mixing ratio (560 p.p.t.v.) was maintained throughout the experiment when a Petri dish, without soil, was placed in the bag. Thus, absorption of COS to the inner surface of the bag, and to the glass, was negligible. The COS mixing ratio in the bag that contained the sterilized soil gradually increased from 540 p.p.t.v. to a level of 1910 p.p.t.v. at $30 \mathrm{~h}$, indicating that sterilization of the soil by autoclaving resulted in abiotic emission of COS. Therefore, the degradation of ambient levels of COS was evaluated based on the overall balance between emission from the sterilized soil and degradation by the bacterium.

Mycobacterium spp. THI401, THI404 and THI405 produced decreases in the level of COS to 330,410 and 350 p.p.t.v., respectively, in $30 \mathrm{~h}$, indicating that these

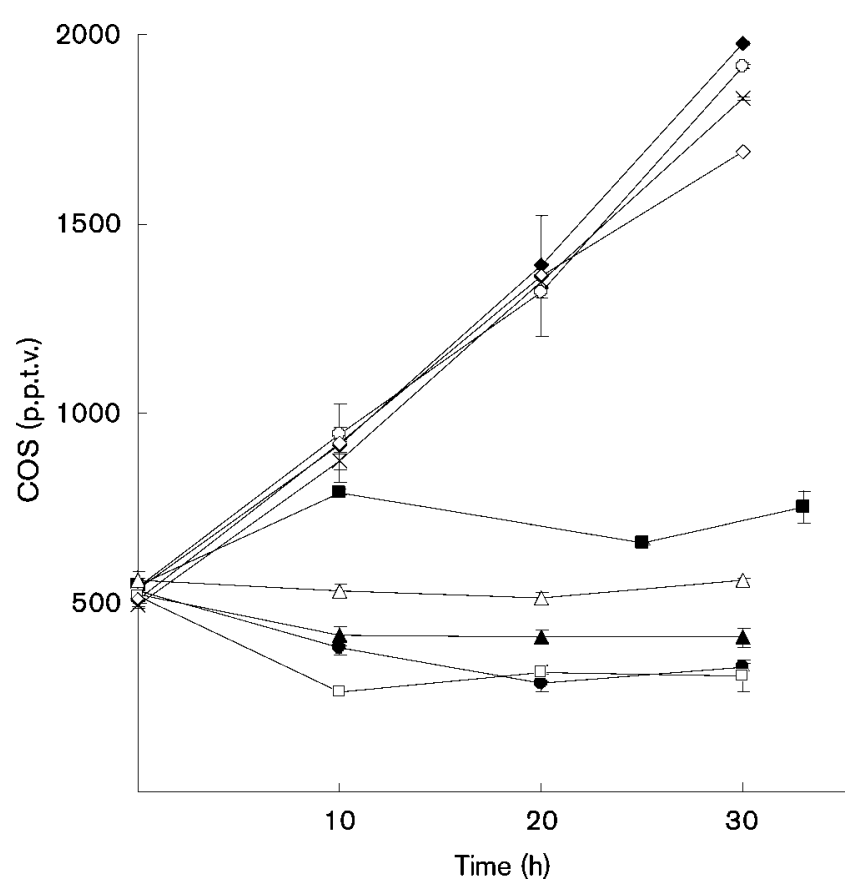

Fig. 4. Bacterial degradation of COS present at an ambient level in the soil. ๑, Mycobacterium sp. THI401;, Mycobacterium sp. THI402; $\boldsymbol{\Delta}$, Mycobacterium sp. THI404; $\square$, Mycobacterium sp. THI405; $\diamond$, Williamsia sp. THI410; Cupriavidus sp. THI414; X, Cupriavidus sp. THI415; $\bigcirc$, uninoculated sterilized soil; $\triangle$, Petri dish without soil. The points on the curves represent mean values of duplicates - deviation from the mean was less than $20 \%$. The error bars indicate the maximum and the minimum values.

isolates degraded COS at a rate that was faster than that for COS emission from the sterilized soil. COS degradation by Mycobacterium sp. THI402 was at a lower rate than that for the other mycobacterial isolates; however, COS emission from the soil and COS degradation were balanced at about 750 p.p.t.v. These results clearly showed that these mycobacterial isolates exhibited degradation of ambient levels of COS in soil. In contrast, Williamsia sp. THI410, and Cupriavidus spp. THI414 and THI415, produced a gradual increase in the level of COS that was similar to that produced in sterilized soil; thus, they showed little or no biological degradation of ambient levels of COS.

\section{DISCUSSION}

COS-degrading bacteria were found in different types of soil. It should be noted that no selection based on exposure to elevated levels of COS was conducted during the isolation of the bacteria; however, COS-degrading bacteria were obtained from all the soil samples tested. This finding indicates that COS-degrading bacteria may be widely distributed in various types of soil. This is consistent with the report that a soil column exhibits COS degradation immediately after loading of COS (Saito et al., 2002), 
indicating that soil microbes are ready to degrade COS, despite no acclimation period to an elevated level of COS.

The ability to degrade an ambient mixing ratio of COS was examined when the isolate was incubated in soil. However, autoclave sterilization of soil resulted in COS emission from the soil. Nguyen et al. (1995) reported COS emission from biomass burning in field experiments, and it is likely that heat treatment by autoclaving brought about COS emission from the soil. On the other hand, Mycobacterium spp. showed a significant decrease in the ambient level of COS. To compare these COS-uptake rates obtained in soil with previously reported data, the COS degradation rates of the bacteria were calculated on the basis of the difference in the COS mixing ratio at times 0 and $10 \mathrm{~h}$ (Fig. 4). The net rates of COS degradation by THI401 and THI405, for example, were 0.14 and $0.24 \mathrm{pmol} \mathrm{m}^{-2} \mathrm{~s}^{-1}$, respectively. Because the rate of COS emission from the soil was $0.38 \mathrm{pmol} \mathrm{m}^{-2} \mathrm{~s}^{-1}$, the gross levels of reduction in COS were 0.52 and $0.62 \mathrm{pmol} \mathrm{m}^{-2} \mathrm{~s}^{-1}$ for THI401 and THI405, respectively. These values are of a similar order of magnitude to the COS uptake rate of $0.81 \mathrm{pmol} \mathrm{m}^{-2} \mathrm{~s}^{-1}$ that was obtained from a soil experiment (Steinbacher et al., 2004). These results indicate that when there are ambient levels of COS, soil bacteria seem to have the potential to contribute to COS consumption in a soil environment.

Of the isolates examined so far, those that exhibited the ability to degrade ambient levels of COS in soil were found to belong to the genus Mycobacterium. Considering the abundance of mycobacteria in the soil environment (Iivanainen et al., 1997), it is important to understand the mechanism and the prevalence of COS-degradation activity by Mycobacterium spp. CA has been purified from Mycobacterium tuberculosis H37Rv (Suarez Covarrubias et al., 2005), which is a slow-growing strain; however, conversion of an ambient mixing ratio of COS by bacteria carrying CA has not yet been examined. A chemolithoautotrophic bacterium, Thiobacillus thioparus, can utilize COS as a sole energy source (Smith \& Kelly, 1988), and a relevant COS-degrading enzyme has been purified from $T$. thioparus (unpublished results). The role of COS metabolism in the microbial growth and/or energetics of the chemo-organotrophic bacteria isolated here remains to be examined.

In this study, we isolated COS-degrading bacteria, and compared their COS-degradation activities in different cultural conditions of artificial medium and soil, under different mixing ratios of COS at 30 p.p.m.v. and ambient levels. Further studies are in progress to elucidate the enzymic characteristics of these COS-degrading bacteria.

\section{ACKNOWLEDGEMENTS}

Part of this study was supported by a Grant-in-aid for Scientific Research (No. 19800816, No. 17201007 and No. 18310020) from The Ministry of Education, Culture, Sport, and Technology of Japan.

\section{REFERENCES}

Altschul, S. F., Gish, W., Miller, W., Myers, E. W. \& Lipman, D. J. (1990). Basic local alignment search tool. J Mol Biol 215, 403-410.

Andreae, M. O. \& Crutzen, P. J. (1997). Atmospheric aerosols: biogeochemical sources and role in atmospheric chemistry. Science 276, 1052-1058.

Badger, M. R. \& Price, G. D. (1990). Carbon oxysulfide is an inhibitor of both $\mathrm{CO}_{2}$ and $\mathrm{HCO}_{3}^{-}$uptake in the cyanobacterium Synechococcus PCC7942. Plant Physiol 94, 35-39.

Bandy, A. R., Thornton, D. C., Scott, D. L., Lalevic, M., Lewin, E. E. \& Driedger, A. R., III (1992). A time series for carbonyl sulfide in the northern hemisphere. J Atmos Chem 14, 527-534.

Bremner, J. M. \& Banwart, W. L. (1976). Sorption of sulfur gases by soils. Soil Biol Biochem 8, 79-83.

Castro, M. S. \& Galloway, J. N. (1991). A comparison of sulfur-free and ambient air enclosure techniques for measuring the exchange of reduced sulfur gases between soils and the atmosphere. J Geophys Res 96, 15427-15437.

Chengelis, C. P. \& Neal, R. A. (1979). Hepatic carbonyl sulfide metabolism. Biochem Biophys Res Commun 90, 993-999.

Chin, M. \& Davis, D. D. (1995). A reanalysis of carbonyl sulfide as a source of stratospheric background sulfur aerosol. J Geophys Res 100, 8993-9006.

Conrad, R. (1996). Soil microorganisms as controllers of atmospheric trace gases $\left(\mathrm{H}_{2}, \mathrm{CO}, \mathrm{CH}_{4}, \mathrm{OCS}, \mathrm{N}_{2} \mathrm{O}\right.$ and $\left.\mathrm{NO}\right)$. Microbiol Rev 60, 609-640.

Conrad, R. \& Meuser, K. (2000). Soils contain more than one activity consuming carbonyl sulfide. Atmos Environ 34, 3635-3639.

Crutzen, P. J. (1976). The possible importance of CSO for the sulfate layer of the stratosphere. Geophys Res Lett 3, 73-76.

Elliott, S., Lu, E. \& Rowland, F. S. (1989). Rates and mechanisms for the hydrolysis of carbonyl sulfide in natural waters. Environ Sci Technol 23, 458-461.

Ferm, R. J. (1957). The chemistry of carbonyl sulfide. Chem Rev 57, 621-640.

Gries, C., Nash, T. H., III \& Kesselmeier, J. (1994). Exchange of reduced sulfur gases between lichens and the atmosphere. Biogeochemistry 26, 25-39.

livanainen, E. K., Martikainen, P. J., Räisänen, M. L. \& Katila, M. L. (1997). Mycobacteria in boreal coniferous forest soils. FEMS Microbiol Ecol 23, 325-332.

Katayama, Y., Narahara, Y., Inoue, Y., Amano, F., Kanagawa, T. \& Kuraishi, H. (1992). A thiocyanate hydrolase of Thiobacillus thioparus. A novel enzyme catalyzing the formation of carbonyl sulfide from thiocyanate. J Biol Chem 267, 9170-9175.

Kesselmeier, J., Teusch, N. \& Kuhn, U. (1999). Controlling variables for the uptake of atmospheric carbonyl sulfide by soil. J Geophys Res 104, 11577-11584.

Kuhn, U., Ammann, C., Wolf, A., Meixner, F. X., Andreae, M. O. \& Kesselmeier, J. (1999). Carbonyl sulfide exchange on an ecosystem scale: soil represents a dominant sink for atmospheric COS. Atmos Environ 33, 995-1008.

Lehmann, S. \& Conrad, R. (1996). Characteristics of turnover of carbonyl sulfide in four different soils. J Atmos Chem 23, 193-207.

Miller, A. G., Espie, G. S. \& Canvin, D. T. (1989). Use of carbon oxysulfide, a structural analog of $\mathrm{CO}_{2}$, to study active $\mathrm{CO}_{2}$ transport in the cyanobacterium Synechococcus UTEX 625. Plant Physiol 90, 1221-1231.

Muyzer, G., Teske, A., Wirsen, C. O. \& Jannasch, H. W. (1995). Phylogenetic relationships of Thiomicrospira species and their 
identification in deep-sea hydrothermal vent samples by denaturing gradient gel electrophoresis of 16S rDNA fragments. Arch Microbiol 164, 165-172.

Nguyen, B. C., Mihalopoulos, N., Putaud, J. P. \& Bonsang, B. (1995). Carbonyl sulfide emissions from biomass burning in the tropics. J Atmos Chem 22, 55-65.

Protoschill-Krebs, G. \& Kesselmeier, J. (1992). Enzymatic pathways for the consumption of carbonyl sulphide (COS) by higher plants. Bot Acta 105, 206-212.

Protoschill-Krebs, G., Wilhelm, C. \& Kesselmeier, J. (1995). Consumption of carbonyl sulphide by Chlamydomonas reinhardtii with different activities of carbonic anhydrase (CA) induced by different $\mathrm{CO}_{2}$ growing regimes. Bot Acta 108, 445-448.

Saito, M., Honna, T., Kanagawa, T. \& Katayama, Y. (2002). Microbial degradation of carbonyl sulfide in soils. Microbes Environ 17, 32-38.

Simmons, J. S., Klemedtsson, L., Hultberg, H. \& Hines, M. E. (1999). Consumption of atmospheric carbonyl sulfide by coniferous boreal forest soils. J Geophys Res 104, 11569-11576.
Smith, N. A. \& Kelly, D. P. (1988). Oxidation of carbon disulphide as the sole source of energy for the autotrophic growth of Thiobacillus thioparus strain TK-m. J Gen Microbiol 134, 3041-3048.

Steinbacher, M., Bingemer, H. G. \& Schmidt, U. (2004). Measurements of the exchange of carbonyl sulfide (OCS) and carbon disulfide $\left(\mathrm{CS}_{2}\right)$ between soil and atmosphere in a spruce forest in central Germany. Atmos Environ 38, 6043-6052.

Suarez Covarrubias, A., Larsson, A. M., Högbom, M., Lindberg, J., Bergfors, T., Björkelid, C., Mowbray, S. L., Unge, T. \& Jones, T. A. (2005). Structure and function of carbonic anhydrases from Mycobacterium tuberculosis. J Biol Chem 280, 18782-18789.

Torres, A. L., Maroulis, P. J., Goldberg, A. B. \& Bandy, A. R. (1980). Atmospheric OCS measurements on project Gametag. J Geophys Res 85, 7357-7360.

Watts, S. F. (2000). The mass budgets of carbonyl sulfide, dimethyl sulfide, carbon disulfide and hydrogen sulfide. Atmos Environ 34, 761-779.

Edited by: H. L. Drake 